\title{
Immunohistochemical localization of protein gene product 9.5 (PGP 9.5) in sensory paraneurons of the rat
}

\author{
Toshihiko Iwanaga, Hongxia Han, Hiroaki Kanazawa and Tsuneo Fujita \\ Department of Anatomy, Niigata University School of Medicine, Asahimachi, Niigata 951, Japan
}

\begin{abstract}
Protein gene product 9.5 (PGP 9.5), a neuron-specific cytoplasmic protein, has recently been confirmed to be present extensively in endocrine paraneurons. The present immunohistochemical study examines its localization in sensory paraneurons in the rat. The immunoreactivity for PGP 9.5 was found in olfactory receptor cells, taste bud cells and vestibular hair cells, but not in the hair cells of Corti's organ or rod and cone cells in the retina. This finding indicates the availability of PGP 9.5 as a marker substance for certain sensory cells, and adds it to a list of 'neuron-specific' proteins which are shared by paraneurons.
\end{abstract}

Immunohistochemistry using antisera against neuron-specific proteins has proved to be a useful tool for selectively staining neuronal elements; it furthermore has revealed the existence of those proteins in non-neuronal cells which are categorized as sensory and endocrine paraneurons (3). Neuronspecific enolase (NSE), and spot 35 protein, originally isolated as a cerebellum-specific protein, are representatives of such neuron-specific proteins (6). The dual distribution of the proteins in neurons and paraneurons, which failed to be accounted for by ontogenetical aspects, seems to reflect that certain unknown mechanisms in the cellular metabolism might be shared by these cell groups (3).

Protein gene product 9.5 (PGP 9.5) (7) is a cytoplasmic protein predominantly contained in neurons of the central and peripheral nervous systems $(4,11,14,15,17)$. Like NSE and spot 35 protein, this 'neuron-specific' protein is also expressed in several endocrine paraneurons including anterior pituitary cells, thyroid parafollicular cells, adrenal medullary cells, and endocrine cells in the pancreas and stomach $(14,15)$. The expression of PGP 9.5 in the endocrine paraneurons reminds us of its possible existence in sensory paraneurons, as we have confirmed the extensive localization of NSE and spot 35 protein in the sensory paraneurons $(5,6)$. The present study is first to report this immunoreactivity for PGP 9.5 in several sensory paraneurons of rats.

Male Wistar rats, weighing 200-250 g, were used in this study. The animals were anesthetized with pentobarbital and perfused with a physiological saline followed by $4 \%$ paraformaldehyde solution (in $0.1 \mathrm{M}$ phosphate buffer, $\mathrm{pH} 7.4$ ). The nasal mucosa, tongue, eyeball and inner ear were removed and immersed in the same fixative for an additional $6 \mathrm{~h}$. After fixation, the nasal mucosa and inner ear were decalcified in Plank-Rychlo's solution for $1 \mathrm{~h}$. The tissues mentioned above were immersed in 30\% sucrose solution and rapidly frozen in liquid nitrogen. Frozen sections were prepared in a cryostat (Coldtome CM 41, Sakura) and processed for the avidin-biotin complex (ABC) method. The antiserum used in this study was a rabbit anti-PGP 9.5 serum purchased from Ultraclone (Cambridge, U.K.). The sections were incubated overnight with the antiserum diluted to $1: 3,000$. The reactions of the antigen-antibody were visualized by a Streptoavidin-biotin staining kit (Nichirei, Histofine SAB-PO, Tokyo).

The characterization of the antiserum has been described elsewhere (14). The specificity of the immunoreactions was checked by incubating the sections with a normal rabbit serum as the first layer. A preabsorption test with the corresponding antigen was not performed, because the antigen was not available. The immunoreactivity of sensory paraneurons demonstrated in the present study showed the same staining property as that of neural elements when the antiserum was gradually 
diluted.

In the olfactory mucosa, virtually all receptor cells, namely olfactory cells, were intensely immunoreactive for PGP 9.5 through the entire length of the cell body; olfactory vesicles, i.e., the terminal swellings of the apical cell processes were more intensely immunoreactive than other parts of the cell (Fig. 1). The axons of the olfactory cells in the epithelium and the lamina propria were less intensely stained and frequently unclear, possibly due to their small diameter. No supporting cells or basal cells in the epithelium showed any positive reaction. Positive immunoreactivity was also recognized in nerve fibers of various sizes throughout the lamina propria. They included nerve fascicles derived from the receptor cells, and thick nerve bundles of the trigeminal nerve located in the deeper region of the lamina propria. The respiratory area of the nasal mucosa was characterized by the wealth of immunoreactive intraepithelial nerve fibers, fine and beaded in appearance. A small number of immunoreactive cells were found dispersed within the respiratory epithelium (Fig. 2). The immunoreactive cells were more numerous in the region where the nasal glands were developed, but rare in the region adjacent to the olfactory area. They were columnar or pyramidal in shape and appeared to be equipped with a tuft of microvilli or cilia.

In the circumvallate papillae of the tongue, the immunoreactivity for PGP 9.5 was found within the taste buds, where several slender cells extending from the base to the taste pore were moderately immunolabeled (Fig. 3). They were intermingled with immunonegative cells in the single taste buds. The frequency of occurrence of the positive cells varied according to taste bud, some taste buds lacking the positive cells. The immunoreactivity was also localized in numerous nerve fibers within the taste buds and in nerves densely distributed in the lamina propria (Fig. 3).

The receptor cells in the inner ear, namely hair cells, showed varying stainability to the PGP 9.5 antiserum according to the kinds of organs. The hair cells in the organ of Corti were negative in reaction. Definite immunoreactivity in the Corti's organ was restricted to the afferent nerve endings contacting the basal portion of the hair cells (Fig. 4). In the vestibular organs, on the other hand, the sensory epithelium in the maculae of the utricle and saccule, and the crista ampullaris were stained as a whole, because the hair cells and supporting cells were both immunoreactive (Figs. 5-7). The hair cells, occasionally including the hairs, were more intensely immunolabeled (Fig. 6).

In the retina, the outer granular layer and the layer of rods and cones contained no cellular elements immunoreactive for PGP 9.5. Thus the visual receptor cells could not be immunostained at all. The immunoreactivity was recognized in ganglion cells and their afferent fibers in the innermost layer of the retina and also in horizontal cells dispersed in the external part of the inner granular layer (Fig. 8). Round cell-bodies in the internal part of the inner granular layer were moderately immunolabeled and intermingled with immunonegative ones. The choroid membrane contained numerous nerve elements showing the intense immunoreactivity for PGP 9.5.

As expected, the immunoreactivity for PGP 9.5 could be demonstrated in sensory paraneurons including the olfactory receptor cells, taste bud cells and vestibular hair cells. However, we failed to stain cochlear hair cells and visual cells. To date, only a few reports have been available concerning the occurrence of PGP 9.5 immunoreactivity in sensory cells. In the skin, Wang et al. (17) demonstrated PGP 9.5-immunoreactive rounded cells which were distributed in cell clusters within the stratum basale, and regarded them as Merkel cells and/or melanocytes. The intense immunoreactivity in Markel cells was demonstrated by Dalsgaard et al. (2) and Ramieri et al. (11) in the skin and the gingival epithelium of the human, respectively. The immunoreactivity was reported by Lauweryns and

Fig. 1 PGP 9.5 immunoreactivity in the nasal mucosa of a rat. Numerous receptor cells are selectively immunolabeled. The olfactory vesicles (bulbus dendriticus) are more intense in immunoreaction. No immunoreactive cells are seen in the respiratory area (R). $\times 760$

Fig. 2 The respiratory area of the nasal mucosa. The PGP 9.5-immunoreactive cells are scattered in the epithelial lining. Immunopositive nerve fibers are distributed within the epithelium (an arrow) and in the nasal glands $(\mathrm{G}) . \times 760$

Fig. 3 Taste buds in the circumvallate papilla of a rat. Some slender cells indicated by arrows are moderately immunoreactive for PGP 9.5. The taste buds contain numerous immunolabeled nerve fibers. $\times 760$

Fig. 4 The PGP 9.5 immunoreactivity in the organ of Corti. The immunoreactivity is localized in nerve terminals contacting the basal part of the outer hair cells. $\times 760$ 

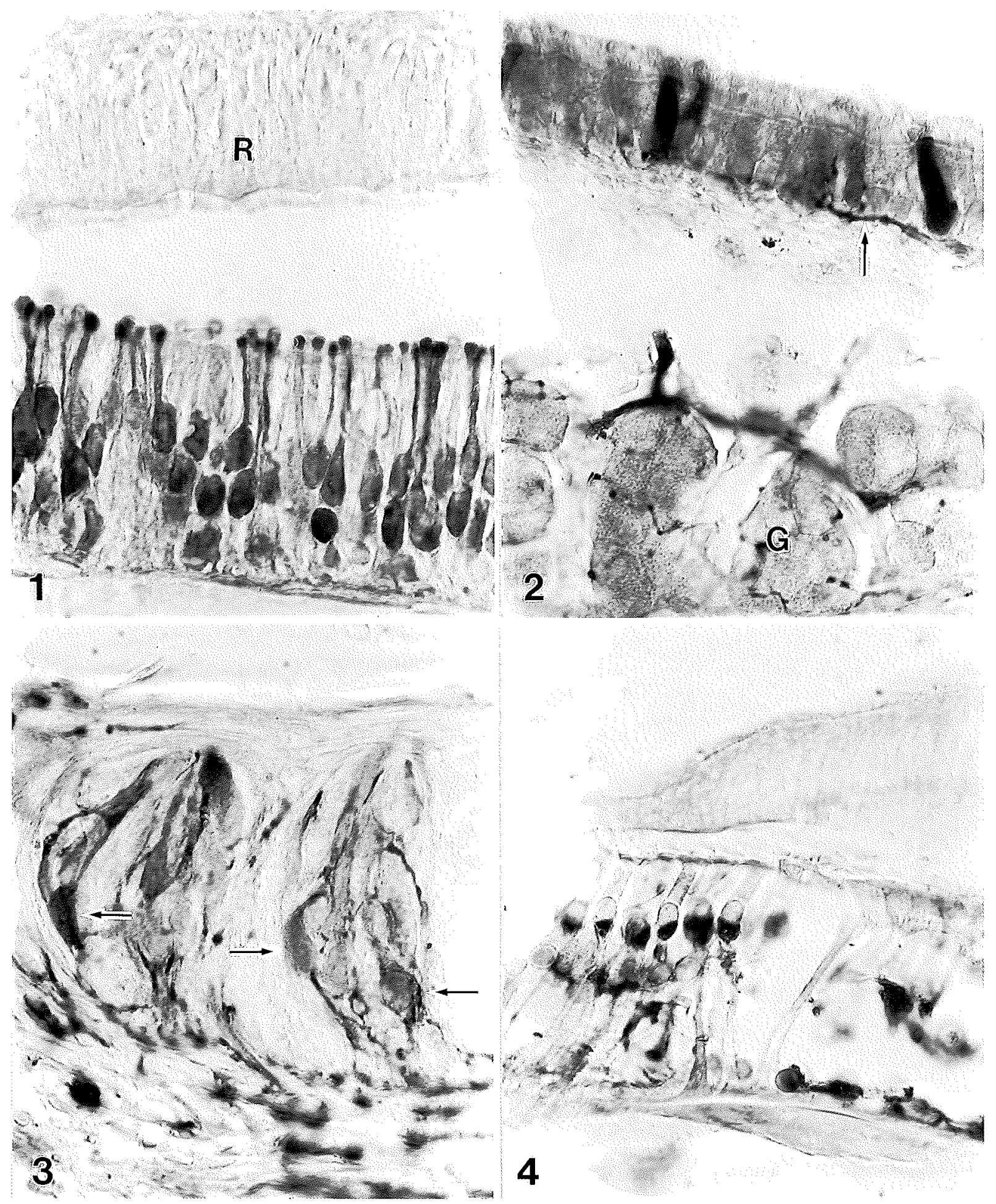

Figs. 1-4 


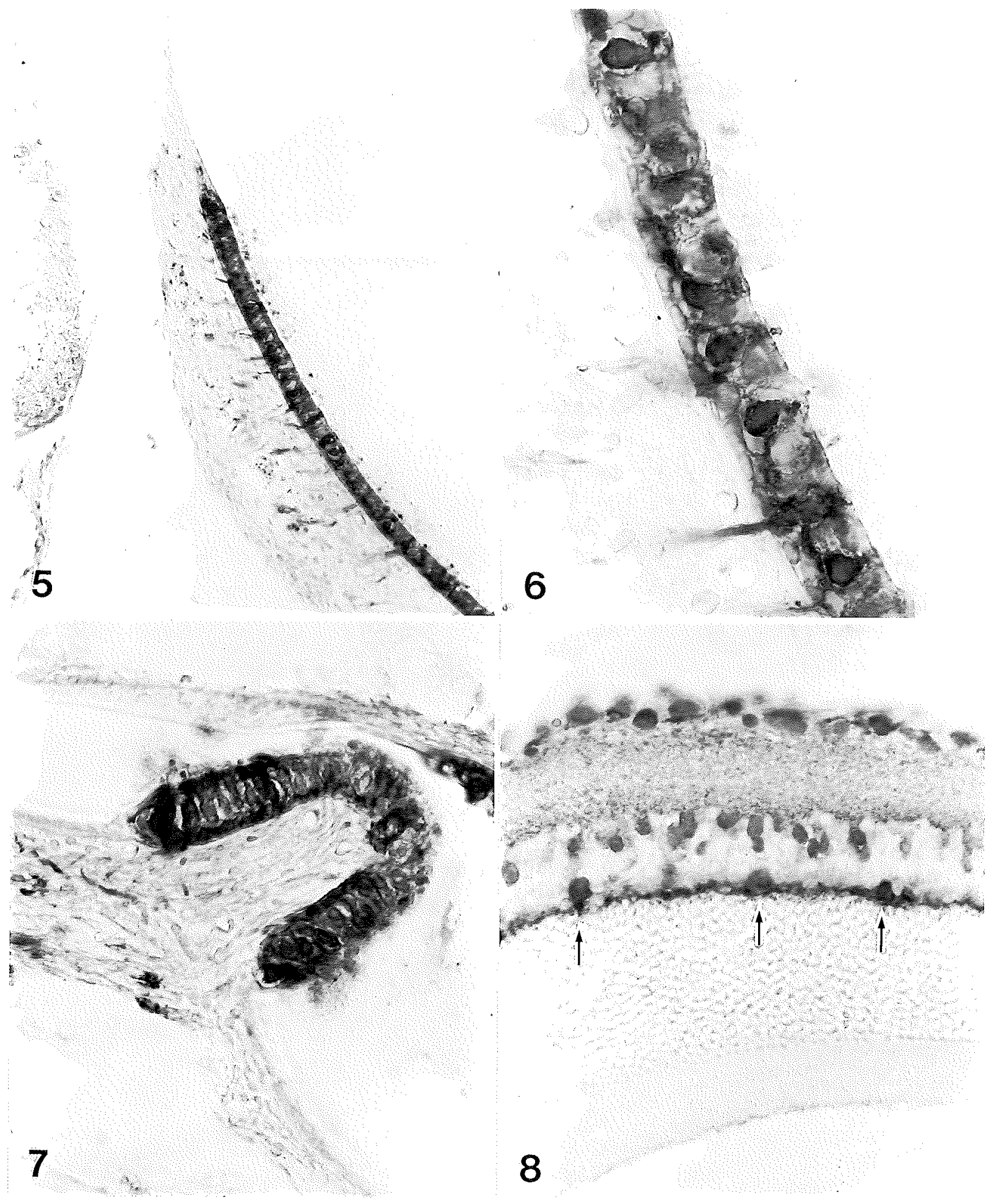

Figs. 5-7 The PGP 9.5 immunoreactivity in the inner ear. The sensory epithelium in the maculae of the utricle (Figs. 5 and 6) and the crista ampullaries (Fig. 7) is moderately immunoreactive as a whole. In Fig. 6, hair cells are more intensely immunolabeled. Fig. 5: × 190, Fig. 6: $\times 760$, Fig. 7: $\times 380$

Fig. 8 The PGP 9.5 immunoreactivity in the retina. Ganglion cells and rounded cells in the inner granular layer are immunostained. More intense reactivity is seen in horizontal cells (arrows) and their processes. $\times 300$ 
Van Ranst (8) in the pulmonary sensory cells of the neuroepithelial bodies in several mammalian species.

Among the sensory paraneurons examined in the present study, the most intense and selective immunoreactivity for PGP 9.5 was found in the olfactory receptor cells. Olfactory marker protein (OMP) and NSE have been used as the specific markers for the cells in mammals $(10,13)$. PGP 9.5 is the third marker substance for the olfactory receptor cells. This protein has advantages over NSE and OMP due to its more intense immunoreactivity. It remains unclear whether the immunoreactive cells dispersed in the respiratory area might represent another type of receptor cell, e.g., brush cells $(9,12)$ or a special type of ciliated cell. The brush cells are believed to be sensory in nature and widely distributed in the epithelial lining of the airway, including the respiratory region of the nasal mucosa (16).

It is generally accepted that the taste buds consist of four types of cells: type I, II, III and basal cells (19). The type I cells, often called dark cells, are regarded as supporting or sustentacular cells. The type II cells, which are in contact with nerve terminals but lack vesicular elements, are of unknown nature. Type III cells have been identified as the taste receptor cells because of their synaptic contact with afferent nerve terminals. The type III cells are characterized by small clear and large dense vesicles, in which transmitter-like substances may be packed. Yoshie et al. $(18,20)$ demonstrated that type III cells were immunoreactive for NSE and another brain-specific protein, spot 35 protein. The present study demonstrated the PGP 9.5 immunoreactivity in restricted types of cells in the taste buds. It is most likely that the PGP 9.5-immunoreactive cells are identical to type III cells. This idea is supported by an ultrastructural observation of PGP 9.5-immunoreactive cells in the taste buds of the rat (H. Kanazawa, unpublished data).

The immunohistochemical localization of PGP 9.5 in the auditory organs is complicated. The differing immunostainability of the hair cells between the vestibular organs and Corti's organ can not be explained at the present time. The lack of the immunoreactivity for PGP 9.5 in cochlear hair cells is in strong contrast to that for NSE and spot 35 protein, which are both obviously demonstrated in these hair cells $(1,5)$.

Visual cells have been distinguished from other sensory paraneurons with regard to the existence of neuron-specific substances: rod and cone cells have been shown to contain neither NSE nor spot 35 protein, both reliable markers for paraneurons (6). Here again, PGP 9.5 was not demonstrated in the visual cells. The localization of PGP 9.5 in the horizontal cells is comparable with our previous immunohistochemical demonstration that spot 35 protein in the retina was selectively contained in these cells (5).

In conclusion, the novel neuron-specific protein, PGP 9.5 is shown to be shared by certain sensory paraneurons. The selective and intense stainability in the olfactory organ indicates the usefulness of PGP 9.5 as a marker for olfactory receptor cells.

The authors wish to thank Professor Y. Uchiyama and Dr K. Toyama, Department of Anatomy, Iwate Medical University School of Medicine, for their cooperation and encouragement.

Received 2 March 1992; and accepted 12 March 1992

\section{REFERENCES}

1. Altschuler R. A., Reeks K. A., Marangos P. J. and Fex J. (1985) Neuron-specific enolase-like immunoreactivity in inner hair cells but not outer hair cells in the guinea pig organ of Corti. Brain Res. 327, 379-384

2. Dalsgaard C.-J., Rydh M. and Hagerstrand A. (1989) Cutaneous innervation in man visualized with protein gene product 9.5 (PGP 9.5) antibodies. Histochemistry 92, 385-390

3. Fujita T., Kanno T. and Kobayashi S. (1988) The Paraneuron. Springer-Verlag, Tokyo

4. Gulbenkian S., Wharton J. and Polak J. M. (1987) The visualisation of cardiovascular innervation in the guinea pig using an antiserum to protein gene product 9.5 (PGP 9.5). J. Autonom. Nerv. Syst. 18, 235-247

5. Iwanaga T., Takahashi-Iwanaga H., Fujita T., Yamakuni T. and TAKAHASHI Y. (1985) Immunohistochemical demonstration of a cerebellar protein (spot 35 protein) in some sensory cells of guinea pigs. Biomedical Res. 6, 329-334

6. Iwanaga T., Takahashi Y. and Fujita T. (1989) Immunohistochemistry of neuron-specific and glia-specific proteins. Arch. Histol. Cytol. 52, Suppl. 13-24

7. JACKSON P. and ThOMPSON R. J. (1981) The demonstration of new human brain-specific proteins by high-resolution two-dimensional polyacrylamide gel electrophoresis. ' $J$. Neurol. Sci. 49, 429-438

8. Lauweryns J. M. and Van Ranst L. (1988) Protein gene product 9.5 expression in the lungs of humans and other mammals. Immunocytochemical detection in neuroepithelial bodies, neuroendocrine cells and nerves. Neurosci. Lett. 85, 311-316

9. Luciano L., Reale E. and Ruska H. (1968) Über eine "chemorezeptive" Sinneszelle in der Trachea der Ratte. $Z$. Zellforsch. 85, 350-375

10. Monti Graziadei G. A., Margolis F. L., Harding J. W. and Graziadei P. P. C. (1977) Immunohistochemistry of the olfactory marker protein. J. Histochem. Cytochem. 25, 
$1311-1316$

11. Ramieri G., Anselmetti G. C., Baracchi F., Panzica G. C., Viglietti-Panzica C., Modica R. and Polak J. M. (1990) The innervation of human teeth and gingival epithelium as revealed by means of an antiserum for protein gene products 9.5 (PGP 9.5). Amer. J. Anat. 189, 146-154

12. Rhodin J. and Dalhamn T. (1956) Electron microscopy of the tracheal ciliated mucosa in rat. Z. Zellforsch. 44, 345412

13. Takahashi S., Iwanaga T., Takahashi Y., Nakano Y. and Fujita T. (1984) Neuron-specific enolase, neurofilament protein and S-100 protein in the olfactory mucosa of human fetuses. An immunohistochemical study. Cell Tissue Res. 238, 231-234

14. Thompson R. J., Doran J. F., Jackson P., Dhillon A. P. and RoDe J. (1983) PGP 9.5-a new marker for vertebrate neurons and neuroendocrine cells. Brain Res. 278, 224-228

15. Thompson R. J. and DaY I. N. M. (1988) Protein gene product 9.5: a new neuronal and neuroendocrine marker. In Neuronal and Glial Proteins. Structure, Function, and Clinical Application (ed. Marangos P. J., Campbell I. C. and
Cohen R. M.) Academic Press, San Diego, pp. 209-228

16. VoN BRetTSCHNEIDER H. (1958) Elektronenmikroskopische Untersuchungen an der Nasenschleimhaut. Anat. Anz. 105, 194-204

17. Wang L., Hilliges M., Jernberg T., Wiegleb-Edström D. and Johansson O. (1990) Protein gene product 9.5-immunoreactive nerve fibers and cells in human skin. Cell Tissue Res. 261, 25-33

18. Yoshie S., Wakasugi C., Teraki Y., Iwanaga T. and Fujita T. (1988) Immunocytochemical localization of neuron-specific proteins in the taste bud of the guinea pig. Arch. Histol. Cytol. 51, 379-384

19. Yoshie S., Wakasugi C., Teraki Y. and Fujita T. (1990) Fine structure of the taste bud in guinea pigs. I. Cell charcterization and innervation patterns. Arch. Histol. Cytol. 53, 103-119

20. Yoshie S., Wakasugi C., Teraki Y., Iwanaga T. and Fujita T. (1991) Fine structure of the taste bud in guinea pigs. II. Localization of spot 35 protein, a cerebellar Purkinje cell-specific protein, as revealed by electron-microscopic immunocytochemistry, Arch. Histol. Cytol. 54, 113-118 